\title{
The Renin Angiotensin System in Newborn Dogs: Developmental Patterns and Response to Acute Saline Loading
}

\author{
ALFRED DRUKKER, M.D., DAVID I. GOLDSMITH, M.D., ADRIAN SPITZER, M.D., ${ }^{(36)}$ CHESTER M. \\ EDELMANN, JR., M.D., AND M. DONALD BLAUFOX, M.D. \\ WITH THE TECHNICAL ASSISTANCE OF BETH ZAVILOWITZ \\ Department of Pediatrics, Division of Nephrology, Rose F. Kennedy Center, and the Departments of Medicine and \\ Radiology, Albert Einstein College of Medicine, Bronx, New York, USA
}

\section{Summary}

Plasma renin (PRC) and aldosterone concentrations are known to be high during early postnatal life. Whether this is related to the low rates of renal blood flow or to sodium homeostasis remains unknown. Measurements of PRC, renal blood flow, and its intrarenal distribution were performed in 1- to 3-wk-old puppies subjected to maneuvers known to stimulate or inhibit renin release. In the awake state, PRC was observed to be higher in 2-wk-old puppies than in older or younger dogs, $(P<0.0001)$. Significant differences in PRC were also found between litters $(P<0.0001)$, but they did not account for the age-related changes. Anesthesia resulted in a 3- to 5-fold rise in PRC, whereas saline expansion suppressed PRC at all ages, the fall tending to become progressively greater with age $(P<0.09)$. There was no significant correlation between the age-related changes in PRC and those in renal blood flow or its intrarenal distribution. The results of these experiments demonstrate that in the newborn from a qualitative point of view, PRC changes appropriately in response to various stimuli. However, quantitative age-related differences exist in this regard, reflecting an initial immaturity of the feedback system.

\section{Speculation}

The lack of correlation between plasma renin concentration and the intrarenal distribution of blood flow, corroborated with the existence of a relationship between plasma renin and the state of the extracellular fluid volume, suggest that during development the renin-angiotensin-aldosterone system is geared toward the maintenance of the positive sodium balance intrinsic to the process of growth.

The renin-angiotensin-aldosterone system is known to play an important role in the regulation of blood pressure and in sodium homeostasis in the adult animal and human $(4,13,19,20,23,31)$. It also has been implicated in the phenomenon of autoregulation of renal blood flow, single nephron glomerular filtration rate, and intrarenal distribution of blood flow $(1,21,22,28)$. In the newborn period, plasma renin levels are higher by about one order of magnitude than they are later in life $(5,9,11,18)$. This may relate to the low rates of total renal blood flow $(2,14)$ and outer cortical blood flow (2) observed at this age. It is known that the reninangiotensin system can be stimulated in the newborn by peritoneal dialysis or by administration of diuretics $(9,11,29)$, but there is a relative paucity of information regarding its responsiveness to agents known to suppress it in adults $(11,15,27)$, and the results of these studies conflict with each other. Another aspect that needs to be investigated is the relationship between the renin-angiotensin-aldosterone system and sodium homeostasis. The limited na- triuretic response of the newborn following volume expansion might be related to the high plasma concentration of aldosterone. In the present study, normal values of immunoassayable plasma renin concentrations (PRC) were established, the developmental pattern was assessed, and the effect of acute volume expansion on PRC was determined in awake and anesthetized animals of various ages.

\section{METHODS}

Suckling mongrel puppies born in our animal quarters were studied during the first 3 weeks of life. Baseline PRC was determined on 0.1 to $0.2 \mathrm{ml}$ plasma samples obtained in the morning (9 to 10 A.M.) from 173 awake animals. Fifty-six of these puppies were studied serially at 2 to 4 different ages. Thus, the number of baseline determinations exceeds the number of animals studied. Diurnal variation was studied in 15 animals by comparing the values obtained in the morning to those found in samples collected in the afternoon ( 2 to 3 P.M.). All blood samples were obtained from the jugular vein. This necessitated that the puppies be held in a recumbent position with the neck extended. The plasma was separated from red blood cells at $4^{\circ} \mathrm{C}$ in a Sorvall Cold Centrifuge, and the samples were kept frozen at $-40^{\circ} \mathrm{C}$ until the time of analysis.

The effect of volume expansion was evaluated in 13 animals belonging to one of three age groups (4 to 6,11 to 15 , and 19 to 23 days), known to correspond to specific developmental stages of intrarenal blood flow distribution (2).

General anesthesia (stage III, plane 2; Ref. 6) was induced and maintained with ether. PE 50 (Clay Adams, Inc., New York) catheters were placed into the right femoral artery and vein for blood sampling and infusion of saline, respectively. A 33-gauge needle was inserted through a left flank incision into the renal artery at its junction with the aorta for the injection of ${ }^{133} \mathrm{Xe}$ used to determine renal blood flow (2). After surgical preparation, the animal received a $10 \%$ body weight isotonic saline load over a 30 min period. Blood samples for PRC were obtained before and after induction of anesthesia, as well as after the completion of saline expansion.

The effect of saline expansion on PRC was assessed in a separate group of $\mathbf{1 5}$ awake animals. In the early morning hr, the femoral artery and vein were cannulated, and the animal was allowed to awaken and was returned to the litter. Four hr later, the puppy was volume expanded as described above. Blood samples for PRC were obtained before induction of general anesthesia, $4 \mathrm{hr}$ after recovery from anesthesia, and after saline loading.

PRC was determined by the measurement of the generation of angiotensin (A) in the presence of excess homologous substrate $(1678 \pm 205 \mathrm{ng} \mathrm{AI} / 24 \mathrm{hr} / \mathrm{ml})$ and while degradation of AI was blocked by the addition of $8-\mathrm{OH}$ quinoline and dimercaprol. 
Plasma samples $(50 \mu \mathrm{m})$ were mixed with $1.5 \mathrm{ml}$ of substrate rich plasma obtained from adult dogs $48 \mathrm{hr}$ after bilateral nephrectomy and with $15 \mu \mathrm{l}$ of $8-\mathrm{OH}$ quinoline (6.6\%) and dimercaprol (10\%) each. Fifty $\mu \mathrm{l}$ of this mixture were incubated in polystyrene tubes at 4 or $37^{\circ} \mathrm{C}$ for $30 \mathrm{~min}$. The angiotensin contained in the sample was determined by radioimmunoassay with a commercially available kit (E. R. Squibb \& Sons, Inc., Princeton, N.J.), as previously described (7). The coefficient of variance for intraassay and interassay replications were 4.7 and $13.5 \%$, respectively.

\section{RESULTS}

\section{PRC UNDER CONTROL CONDITIONS}

Values of PRC in puppies, expressed as $\mathrm{ng} \mathrm{AI} / \mathrm{ml} \cdot 30 \mathrm{~min}$, were $21.9 \pm 2.9$ (S.E.) $(n=51), 20.4 \pm 1.8(n=57), 48.2 \pm 6.4(n=42)$, and $21.4 \pm 3.8(n=34)$ in the first day, first, second, and third wk of life, respectively (Fig. 1). Thus, PRC rose and then fell during the development of the puppy. Analysis of variance and multiple range testing demonstrated that PRC was significantly greater in 2 -wk-old animals $(P<0.0001)$ than in the other age groups.

The variability between individual observations in each group was due mainly to differences between litters $(P<0.0001)$. This is illustrated in Figure 2, which depicts the mean and S.E. of the values observed from birth to seven days in nine litters, each consisting of at least five puppies. The differences between litters were apparent at each age studied. However, the analysis of variance demonstrated that the increase in PRC noted during the second wk of life remained significant $(P<0.05)$, when the differences between litters were statistically constrained.

No significant difference in PRC was observed $(P>0.2)$ between the samples obtained in the morning (29.6 \pm 6.9) and afternoon (21.2 $\pm 5.7 \mathrm{ng} \mathrm{Al} / \mathrm{ml} \cdot 30 \mathrm{~min}$ ), and no significant correlation could be established between PRC and changes in body weight $(r=0.28)$.

\section{RESPONSE OF PRC TO STIMULI DURING DEVELOPMENT}

The results of the studies regarding the effects of saline expansion on plasma renin in anesthetized animals are shown in Table 1. Anesthesia resulted in a significant increase and saline loading in a decrease in PRC at each age (paired $t$ test), but the latter levels remained above those observed prior to anesthesia. In 2 of

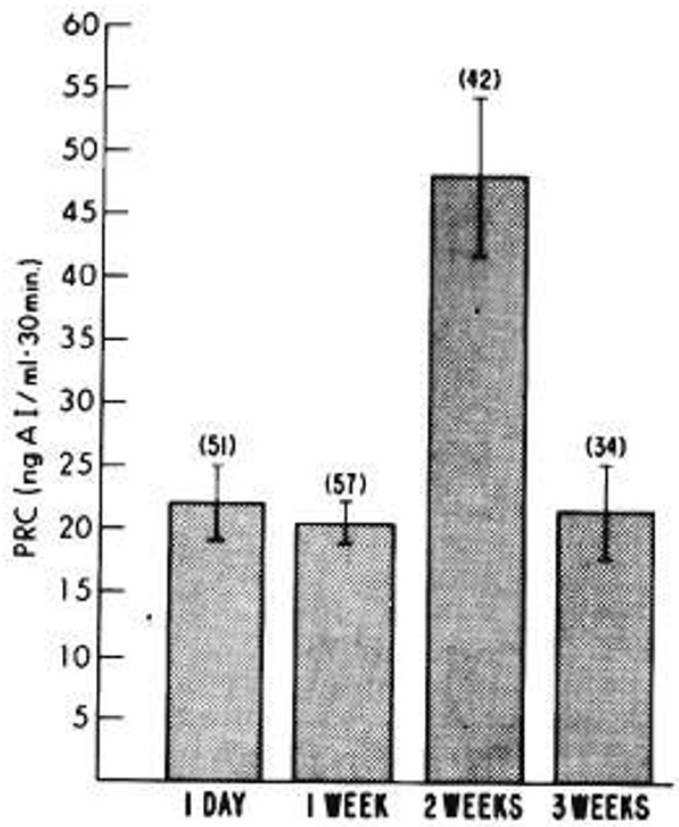

Fig. 1. PRC in unanesthetized puppies of various ages $(\bar{x} \pm$ S.E.). The number of animals studied at each age is given in the brackets at the top of bars.

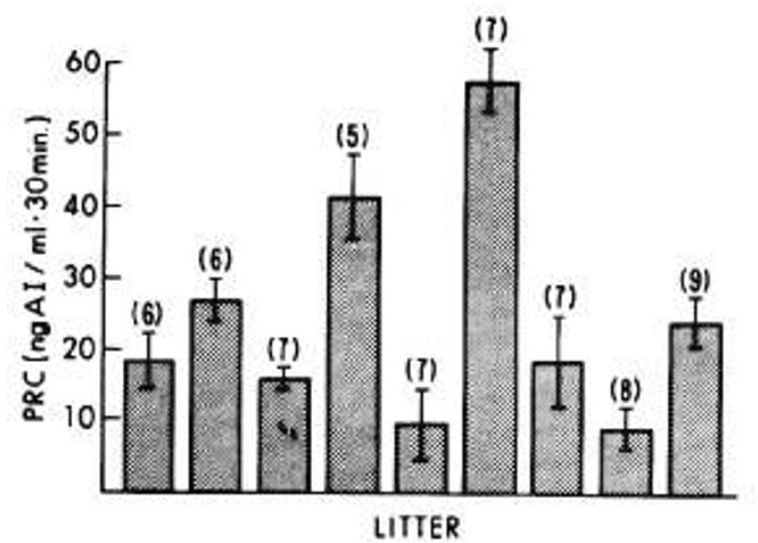

Fig. 2. PRC $(x \pm$ S.E.) in nine litters of awake puppies 0 to 7 days of age. The number of pups in each litter is indicated at the top of bars.

the animals, PRC increased following saline expansion, probably as a result of small variations in the level of anesthesia. There was no significant correlation between the PRC and either mean renal blood flow (RBF), outer cortical flow rate, or the percentage of RBF perfusing the outer cortex (Table 1).

Because these experiments demonstrated that anesthesia results in significant increases in PRC and that saline expansion did not lower PRC to values observed in the control state, the loading studies were repeated in a separate group of 15 animals allowed to recover from the anesthesia used during the placement of femoral catheters. The control values were similar to and not significantly different from those found in the preceding studies (Table 2). Analysis of variance and multiple range testing demonstrated the PRC to be higher at 2 wk than at either 1 or 3 wk of age $(P<0.05)$. Within $4 \mathrm{hr}$ after recovery from anesthesia, PRC returned to preanesthetic levels at all ages $(P>0.3)$. Following expansion with saline, PRC fell to $35.9 \pm 3.5 \%$ of control in the youngest group, to $29.9 \pm 9.3 \%$ in the intermediate age groups, and to $20.0 \pm 4.0 \%$ in the oldest animals. At each age, the fall in PRC was significantly greater than the fall in hematocrit $(P<$ $0.05)$. A tendency toward a progressively larger fall in PRC with age was demonstrated by linear regression $(r=0.47 ; P=0.09)$.

\section{DISCUSSION}

The kidneys of fetal and newborn experimental animals are known to be able to synthesize and secrete renin $(5,9-12,18,24)$, the PRC in the fetus and newborn being generally greater than that of the mother $(5,12,26,29)$. It is also well known that in the newborn plasma renin is very high in both the human and in experimental animals $(9-11,24,29)$. The present study was designed to trace the profile of the changes in PRC during development and to test whether or not procedures known to alter PRC in the adult provoke qualitatively and quantitatively similar responses in maturing animals. In addition, we sought to determine whether or not developmental changes in RBF and its intrarenal distribution correlate with the changes in PRC.

The results obtained confirm that in the puppy PRC is high during the first wk of extrauterine life. New is the observation that PRC is higher during the second wk of life than either during the first or third and that the values found during the latter two periods do not significantly differ from each other. Granger et al. (9), using a bioassay, found plasma renin activity in puppies to be higher during the first two wk than later in life but failed to demonstrate a difference between the one- and two-wk-old animals. One possible reason is the small number of animals $(n=5)$, which were investigated in the second wk of life. Furthermore, the difference might have been obscured by the fact that measurements were not done in littermates; as shown by this study, great variability exists among litters of similar age. It is also possible that a substrate-limited reaction may obtain at an early age and give rise to lower values for plasma renin activity than PRC. 
Table 1. PRC and RBF in anesthetized puppies

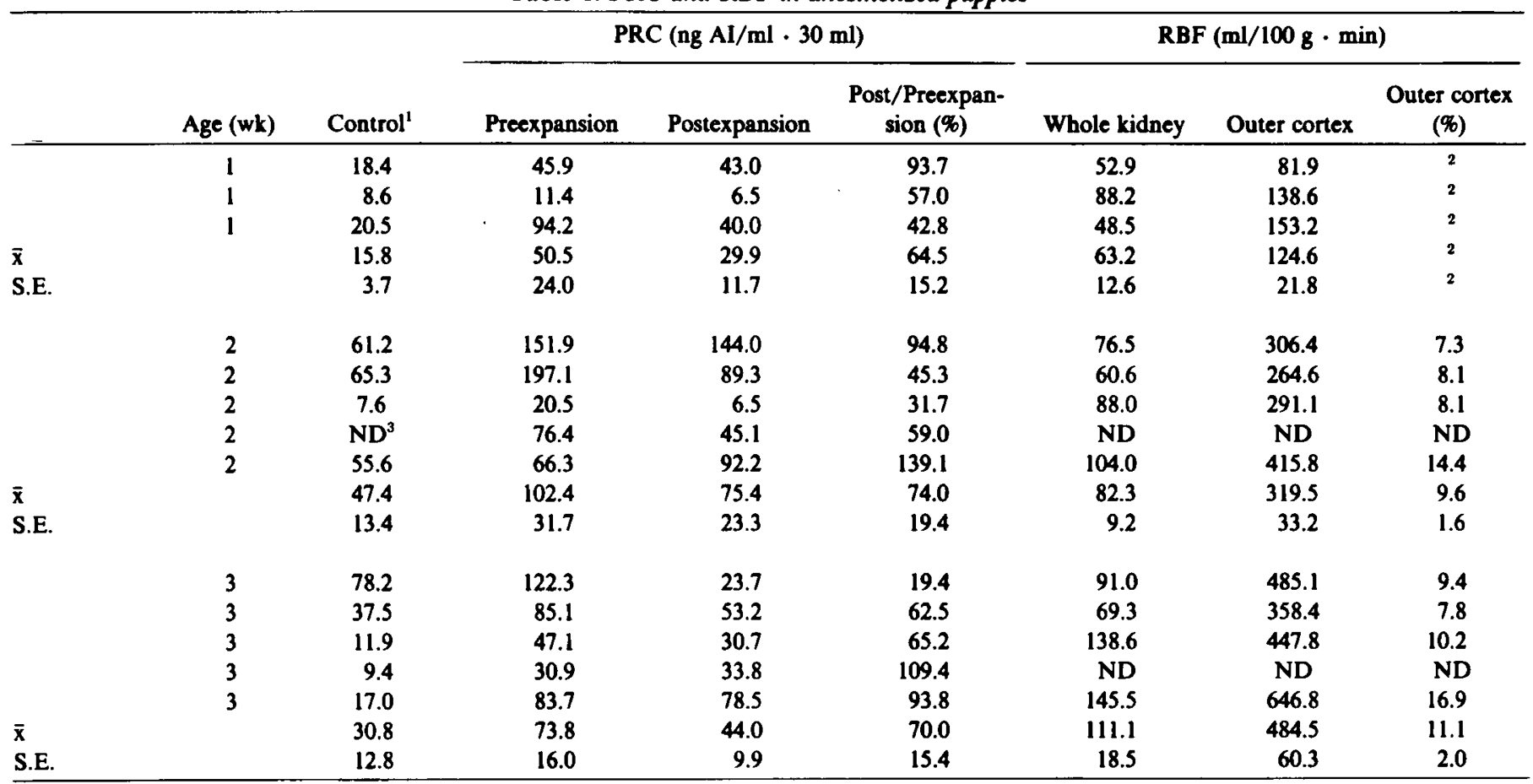

${ }^{1}$ Prior to anesthesia.

${ }^{2}$ Not distinguishable from inner cortical flow.

${ }^{3} \mathrm{ND}$, not done.

Table 2. $P R C^{1}$ in puppies allowed to recover from anesthesia

\begin{tabular}{|c|c|c|c|c|c|}
\hline & Age (wk) & Control $^{2}$ & Preexpansion & Postexpansion & Post/Preexpansion (\%) \\
\hline & 1 & 32.1 & 21.2 & 9.2 & 48.4 \\
\hline & 1 & 20.2 & 47.4 & 12.6 & 26.6 \\
\hline & 1 & 26.1 & 42.6 & 12.7 & 29.8 \\
\hline & 1 & 5.0 & 13.5 & 4.8 & 35.6 \\
\hline$\overline{\mathbf{x}}$ & & 25.3 & 33.4 & 11.6 & $35.9^{3}$ \\
\hline \multirow[t]{5}{*}{ S.E. } & & 6.3 & 6.7 & 2.3 & 3.5 \\
\hline & 2 & 33.0 & 46.0 & 28.0 & 60.9 \\
\hline & 2 & 59.0 & 55.0 & 12.4 & 25.6 \\
\hline & 2 & 95.0 & 32.0 & 21.3 & 36.0 \\
\hline & 2 & 5.0 & 5.0 & 0.2 & 4.0 \\
\hline$\overline{\mathbf{x}}$ & & 49.6 & 45.5 & 15.2 & $29.9^{3}$ \\
\hline \multirow[t]{3}{*}{ S.E. } & & 14.9 & 12.7 & 4.7 & 9.3 \\
\hline & 3 & 4.1 & 14.4 & 1.8 & 12.5 \\
\hline & 3 & 5.7 & 3.5 & 0.9 & 25.7 \\
\hline$\overline{\mathbf{x}}$ & & 9.9 & 22.2 & 4.1 & $20.1^{3}$ \\
\hline S.E. & & 2.7 & 6.7 & 1.3 & 4.1 \\
\hline
\end{tabular}

\footnotetext{
' $\mathrm{ng} \mathrm{Al} / \mathrm{ml} .30 \mathrm{~min}$.

${ }^{2}$ Prior to anesthesia.

${ }^{3}$ Significantly less than $100 \%(P<0.05)$.
}

As in the puppy, plasma renin levels have been found to be high in the human neonate and to decrease thereafter. Kotchen $e t$ al. (18) demonstrated a fall from $8.8 \pm 2.8 \mathrm{ng} \mathrm{AI} / \mathrm{ml} \cdot \mathrm{hr}$ on the first day of life to $2.3 \pm 0.5 \mathrm{ng} \mathrm{AI} / \mathrm{ml} \cdot \mathrm{hr}$ at 3 to $6 \mathrm{wk}$ of age. Hayduk et al. (10) reported that PRC fell from $14.7 \pm 3.1 \mathrm{ng}$ AII/ $\mathrm{ml} \cdot \mathrm{hr}$ at birth to $8.4 \pm 2.8 \mathrm{ng}$ by 3 to 16 days of age. Both of these studies also documented an increase in plasma renin in the first days of life with a subsequent decrease to the levels quoted earlier. Thus, a biphasic pattern is demonstrable in the human neonate as well as in the puppy, although the postnatal ages at which the highest levels are observed appear to differ. It is unlikely that the increase in plasma renin is related solely to the decrease in extracellular volume known to occur after birth. In the study of Hayduk et al. (10), the maximal weight loss of the neonates did not coincide with the increase in PRC. The same holds true for the present study because the animals were in a positive balance for salt and water, as judged from their continuous weight gain, at the time PRC underwent a rise. Moreover, there was no significant correlation between the changes in body weight and PRC in those animals studied on more than one occasion. 
It might be noted that the increase in PRC observed during the second week of life corresponds to the appearance of a zone in the superficial cortex which is perfused at a high rate. The temporal relationship might suggest that the rise in PRC is the consequence of a passive outpouring of renin already stored in the outer cortex. As discussed below, this is not the case.

Because PRC is dependent upon factors related to the intrauterine environment, it was not surprising that at birth the variability between litters was rather great. Several studies have demonstrated the mutual interdependence of the maternal and fetal renin-angiotensin system $(12,26,29)$ as well as the influence of the maternal diet on the level of serum aldosterone in the neonate $(3,8)$. Unforeseen was the persistence of the difference between the litters long after birth. This may be due to the genetic endowment (30) or be dependent on exogenous influences such as the sodium content of maternal milk.

The present experiments explored the responsiveness of PRC to expansion with an isotonic saline solution. In the awake state, sodium loading resulted in a fall in PRC in all animals. The mean decrease in PRC (70.4 $\pm 3.8 \%)$ could not be attributed solely to a dilutional effect because it exceeded the decrease in hematocrit $(32.3 \pm 3.1 \%)$. In addition, these data demonstrate a tendency toward a progressively greater relative fall in PRC with each increment in age $(0.1>P>0.05)$, suggesting that the mechanism responsible for the maintenance of PRC may be less responsive to suppressive exogenous stimuli in the first wk than in the second or third wk of life. This is in agreement with a preliminary report (15), indicating that the relative fall in PRC consequent to daily IP injections of sodium chloride was greater in 3-wk-old puppies than in 1-wk-old animals. It should be clear, however, that the high PRC characteristic of developing animals could not be due solely to the inability to suppress renin release or to a passive outflow of prestored renin because neither of these mechanisms would be expected to be altered by saline expansion alone and presumably PRC would not decrease.

In the anesthetized animals, the suppression of PRC by saline loading was less consistent than in awake animals. In addition, the effect of saline loading was much smaller with only an overall suppression of about $30 \%$, compared to the $67 \%$ decrease found in awake animals. The difference in response to saline observed between awake and anesthetized animals is probably due to the fact that anesthesia alters the renin-angiotensin-aldosterone system. However, even in the anesthetized state, the fall in PRC exceeded that in hematocrit $(P<0.01)$.

The physiologic significance of the high level of PRC in the newborn is yet to be determined. Speculation regarding its role in maintaining the low rates of RBF encountered in early life had to be discarded when experiments using competitive antagonists of angiotensin failed to show an increase in RBF in developing animals (16). The possibility still exists, however, that the high levels of PRC are the consequence of the low renal perfusion pressure. Finally, the relationship between the high level of PRC, high level of aldosterone, and enhanced distal reabsorption of sodium prevailing in the newborn $(17,25)$ needs to be considered. Our finding that the PRC is not fixed but varies with alterations in the state of sodium balance favors the existence of such a relationship.

\section{REFERENCES AND NOTES}

1. Abe, Y., Okahara, T., Kishimoto, T., Yamamoto, K., and Uedo, J.: Relationship between intrarenal distribution of blood flow and renin secretion. Am. J. Physiol., 225: 319 (1973).

2. Aschinberg, L. C., Goldsmith, D. I., Olbing, H., Spitzer, A., Edelmann, C. M. Jr., and Blaufox, M. D.: Neonatal changes in renal blood flow distribution in puppies. Am. J. Physiol., 228: 1453 (1975).

3. Beitins, I. Z., Bayard, F., Levitsky, L., Ances, J. G., Kowarski, A., and Migeon, C. J.: Plasma aldosterone concentration at delivery and during the newborn period. J. Clin. Invest., SI: 386 (1972)

4. Blaufox, M. D., Fromowitz, A., Lee, H. B., Meng, C. H., and Elkin, M.: Renal blood flow and renin activity in renal venous blood in essential hypertension.
Circ. Res., 72: 913 (1970).

5. Broughton Pipkin, F., Kirkpatrick, S. M. L., Lumbers, E. R., and Mott, J. C.: Renin and angiotensin-like levels of foetal, newborn and adult sheep. $J$. Physiol., (Lond.), 218: 385 (1971).

6. Cohen, P. J.: Signs and stages of anesthesia. In: L. S. Goodman and A. Gilman: The Pharmacological Basis of Therapeutics. Ed. 5, pp. 60-65 (Macmillan Publishing Co., Inc., New York, 1970).

7. Chervu, L. R., Lory, M., Liang, T., Lee, H. B., and Blaufox, M. D.: Determination of plasma renin activity by radioimmunoassay: comparison of results from two commercial kits with bioassay. J. Nucl. Med., 13: 806 (1972).

8. Dlouha, H., Erdosova, R., Kraus, M., and Skopkova, J.: The effect of sodium intake on maternal milk electrolytes and aldosterone, corticosterone production in the offspring of rats. Biol. Neonate, 22: 38 (1973).

9. Granger, P., Rojo-Ortega, J. M., Casada Perez, S., Boucher, R., and Genest, J.: The renin-angiotensin system in newborn dogs. Can. J. Physiol. Pharmacol., 49: 134 (1971).

10. Hayduk, K., Krause, D. K., Huenges, R., and Unbehaun, V.: Plasma renin concentration at delivery and during the newborn period in humans. Experientia, 28: 1489 (1972).

11. Hayduk, K., Krause, D. K., and Riegger, G.: Renin and age In: D. K. Krause, W. Hummerich, K. Poulsen: Radioimmunoassay-Renin-Angiotensin. p. 56 (Georg Thieme, Stuttgart, 1978).

12. Hodari, A. A., and Hodgkinson, C. P.: Fetal kidney as a source of renin in the pregnant dog. Am. J. Obstet. Gynecol., 102: 691 (1968).

13. Hollenberg, N. K., Epstein, M., Guttman, R. D., Conroy, M., Basch, R. I., and Merill, J. P.: Effect of sodium balance on intrarenal distribution of blood flow in normal man. J. Appl. Physiol., 28: 312 (1970).

14. Horster, M., and Valtin, H.: Postnatal development of renal functions: micropuncture and clearance studies in the dog. J. Clin. Invest., S0: 779 (1971).

15. John, E. G., Samayoa, C., Zeis, P. M., Wojdula, L., and Aschinberg, L. C. Renin-aldosterone axis response to chronic salt loading and volume contraction in neonatal puppies. Kidney Int. (Abstract), 12: 562 (1977).

16. Jose, P. A., Slotkoff. L. M., Montgomery S., Calcagno, P. L., and Eisner, G.: Autoregulation of renal blood flow in the puppy. Am. J. Physiol., 299: 983 (1975).

17. Kleinman, L. I.: Renal sodium reabsorption during saline loading and distal blockade in newborn dogs. Am. J. Physiol., 228: 1403 (1975).

18. Kotchen, T. A., Strickland, A. L., Rice, T. W., and Walters, D. R.: A study of the renin-angiotensin system in newborn infants. J. Pediatr., 80: 938 (1972).

19. Laragh, J. H.: Vasoconstriction-volume analysis for understanding and treating hypertension: the use of renin and aldosterone profiles. Am. J. Med., 55: 261 (1973).

20. Lowenstein, J., and Steele, J. M., Jr.: Aldosterone production during dietary sodium restriction and Beta-adrenergic blockade. Kidney Int., 11: 128 (1977).

21. Oparil, S., and Haber, E.: The renin-angiotensin system. N. Engl. J. Med., 291: 389, 446 (1974).

22. Peach, J. J.: Renin-angiotensin system. Biochemistry and mechanisms of action. Physiol. Rev., 57: 313 (1977).

23. Peart, W. S., Laragh, J. H., Hickler, R. B., Birkenhager, W. H., Amery, A., and Doyle, A. E.: Report on round table on renin as risk factor in hypertension. Clin. Sci. Mol. Med., 48: 117 (1975).

24. Rojo-Ortega, J. M., Hayduk, K., and Genest, J.: Étude morphodynamique su l'ontogénèse du système rénine-angiotensine. l'Union Med. Can., 102: 787 (1973).

25. Schoeneman, M., and Spitzer, A.: Sodium reabsorption during maturation. Kidney Int. (Abstract), 10: 598 (1976).

26. Smith, F. G., Jr., Bashore, R. A., Rarajas, L., and Lupu, A. N.: Renin-angiotensin system in the fetal sheep. Pediatr. Res. (Abstract), 6: 416 (1972).

27. Solomon, S., Iaina, A., and Eliahou, H.: Possible determinants of plasma renin activity in infant rats. Proc. Soc. Exp. Biol. Med., 153: 309 (1976).

28. Thurau, K., Schnermann, J., Nagel, W., Horster, M., and Wahl, M.: Composition of tubular fluid in the macula densa segment, as a factor regulating the function of the juxtaglomerular apparatus. Circ. Res. (Suppl. II), 20/21 V: 79 (1967)

29. Timper, C. E., and Lumbers, E. R.: The renin-angiotensin system in foetal lambs. Pfluegers Arch. Eur. J. Physiol., 336: 1 (1972).

30. Vincent, M., Dupont, J., and Sussard, J.: Plasma renin activity as a function of age in two new strains of spontaneously hypertensive rats. Clin. Sci. Mol. Med., 50: 103 (1976).

31. Woods, J. W., Pittman, W., Pulliam, C. L., Werk, E., Waider, W., and Allen, C.: Renin profiling in hypertension and its use in treatment with propanolol and chlorthalidone. N. Engl. J. Med., 294: 1137, (1976).

32. Dr. A. Drukker was supported by a postdoctoral fellowship from the Kidney Disease Institute of New York (KDI 70-23).

33. Dr. D. Goldsmith was supported by a training grant of the National Institutes of Health (HL 05267).

34. The present address of Dr. A. Drukker is: Shaare Zedek Hospital, Jaffe Road, Jerusalem, Israel.

35. The authors thank Ms. H. B. Lee for her aid in performing the assays of plasma renin concentration and Ms. V. Mimnaugh for her secretarial assistance.

36. Requests for reprints should be addressed to: Adrian Spitzer, M.D., Department of Pediatrics, Division of Nephrology, Rose F. Kennedy Center, 1410 Pelham Parkway South, Bronx, N.Y. 10461 (USA).

37. This research was supported in part by National Institutes of Health Grants AM 14877 and NHLI 11984 and the New York State Health Research Council.

38. Received for publication May 14, 1979.

39. Received for publication July 31, 1979. 